\title{
Multiple perineural cysts in the cervical, thoracic, and lumbar vertebrae of a mature individual
}

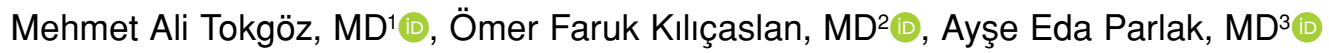 \\ 'Department of Orthopedics and Traumatology, Ankara Keçiören Training and Research Hospital, Ankara, Turkey \\ ${ }^{2}$ Department of Orthopedics and Traumatology, Antalya Training and Research Hospital, Ankara, Turkey \\ ${ }^{3}$ Department of Radiology, Antalya Training and Research Hospital, Ankara, Turkey
}

With the widespread use of modern imaging techniques, perineural cysts have become a common finding with a prevalence of 4.6 to $13.2 \% .^{[1-3]}$ These cysts were first described by Tarlov, and it was reported that the symptomatic ones were mostly located in sacral spine but could also be seen in thoracolumbar region. ${ }^{[4]}$

Most of the cases with perineural cysts are asymptomatic that can be managed conservatively. Only $1 \%$ of patients become symptomatic and present with lower back pain, radicular pain at extremities with sensory changes, pelvic/perineal pain with sensory changes, lower extremity paresis, bowel/bladder/sexual dysfunction, and signs of cerebrospinal fluid hypotension. ${ }^{[2,5]}$ Symptoms could worsen with posture, cough, Valsalva maneuvers, standing, lifting and climbing changes, all of which tend to increase cerebrospinal fluid pressure. ${ }^{[6]}$ The management of symptomatic

Received: July 02, 2020

Accepted: August 06, 2020

Published online: January 06, 2021

Correspondence: Mehmet Ali Tokgöz, MD. Ankara Keçiören Eğitim ve Araştırma Hastanesi Ortopedi ve Travmatoloji Kliniği. 06000 Keçiören, Ankara, Türkiye.

E-mail: m.alitokgoz@gmail.com

Doi: $10.5606 /$ ehc. 2021.77775

Citation: Tokgöz MA, Kılıçaslan ÖF, Parlak AE. Multiple perineural cysts in the cervical, thoracic, and lumbar vertebrae of a mature individual. Jt Dis Relat Surg 2021;32(1):262-266.

(92021 All right reserved by the Turkish Joint Diseases Foundation

This is an open access article under the terms of the Creative Commons Attribution-NonCommercial License, which permits use, distribution and reproduction in any medium, provided the original work is properly cited and is not used for commercial purposes (http://creativecommons.org/licenses/by-nc/4.0/).

\section{ABSTRACT}

A 54-year-old female patient was admitted to our outpatient clinic with back and low back pain. There were no remarkable physical or neurological findings in the two-year followup period of the patient. There were 39 lesions at 17 levels (mean diameter: $5.93 \pm 2.77$ [range, 1.00 to 12.2 ] $\mathrm{mm}$ ) in entire vertebra in magnetic resonance imaging and more than one perineural cysts were observed adjacent to the same nerve root at several vertebrae levels. In this patient, conservative treatment was preferred.

Keywords: Benign spinal lesions, multiple perineural cyst, Tarlov cyst.

perineural cysts is controversial due to limited information. Percutaneous aspiration and fibrin glue injection, lumboperitoneal shunts, and open resection with microsurgical methods are suggested as interventional procedures for perineural cysts. ${ }^{[3]}$

In this article, we present an exceptional case which suffered lumbar and dorsal pain and was incidentally observed to have multiple bilateral perineural cysts that involved almost the entire spine besides sacrum. ${ }^{[7]}$

\section{CASE REPORT}

A 54-year-old female patient was admitted to the outpatient clinic with dorsalgia. There was no history of trauma, rheumatologic disease or any other chronic conditions. Neuromotor functions, bowel/bladder habits, and spinal movements were completely normal. On local spinal examination, no tenderness was elicited. Straight leg raising test and other pain provoking tests were found to be negative. Conventional radiographic examinations of the patient were evaluated as normal. Thoracic and lumbar vertebral regions were examined with 


\section{TABLE I}

Dimensions of perineural cysts detected in magnetic resonance imaging

\begin{tabular}{|c|c|c|c|c|c|}
\hline SNL & $\mathrm{n}(\mathrm{mm})$ & SNL & $\mathrm{n}(\mathrm{mm})$ & SNL & $\mathrm{n}(\mathrm{mm})$ \\
\hline $\mathrm{C} 2-\mathrm{R}$ & 1 & T1-R & 12.2 & L1-R & 4.9 \\
\hline C3-R & 1 & T1-L & 8.8 & L1-L & 6.8 \\
\hline C3-L & 1.2 & T2-R1 & 7.5 & L2-R & 11 \\
\hline $\mathrm{C} 4-\mathrm{R}$ & 3.2 & T2-R2 & 4.9 & L2-L & 5.4 \\
\hline C4-L & 2.8 & T2-L & 8.2 & L3-R & 7.8 \\
\hline C5-R1 & 3.5 & T4-R & 5.2 & L3-L & 8.5 \\
\hline C5-R2 & 4.8 & T10-R & 6.5 & L4-R & 6 \\
\hline C5-L & 5.2 & T10-L & 3.3 & L4-L & 5.8 \\
\hline $\mathrm{C} 6-\mathrm{R} 1$ & 1.4 & T11-R & 10 & L5-R & 6 \\
\hline $\mathrm{C} 6-\mathrm{R} 2$ & 2.9 & T11-L1 & 7.7 & L5-L & 9 \\
\hline C6-R3 & 5.9 & T11-L2 & 6.8 & & \\
\hline C6-L1 & 3.4 & T12-R & 6.5 & & \\
\hline C6-L2 & 4.3 & T12-L & 6.8 & & \\
\hline C6-L3 & 7.2 & & & & \\
\hline C8-R & 10.2 & & & & \\
\hline C8-L & 7.7 & & & & \\
\hline Mean & 4.11 & & 7.27 & & 7.12 \\
\hline Overall mean & & & \multicolumn{2}{|c|}{$5.93 \pm 2.77$ (range, 1.00 to 12.2 ) } & \\
\hline
\end{tabular}
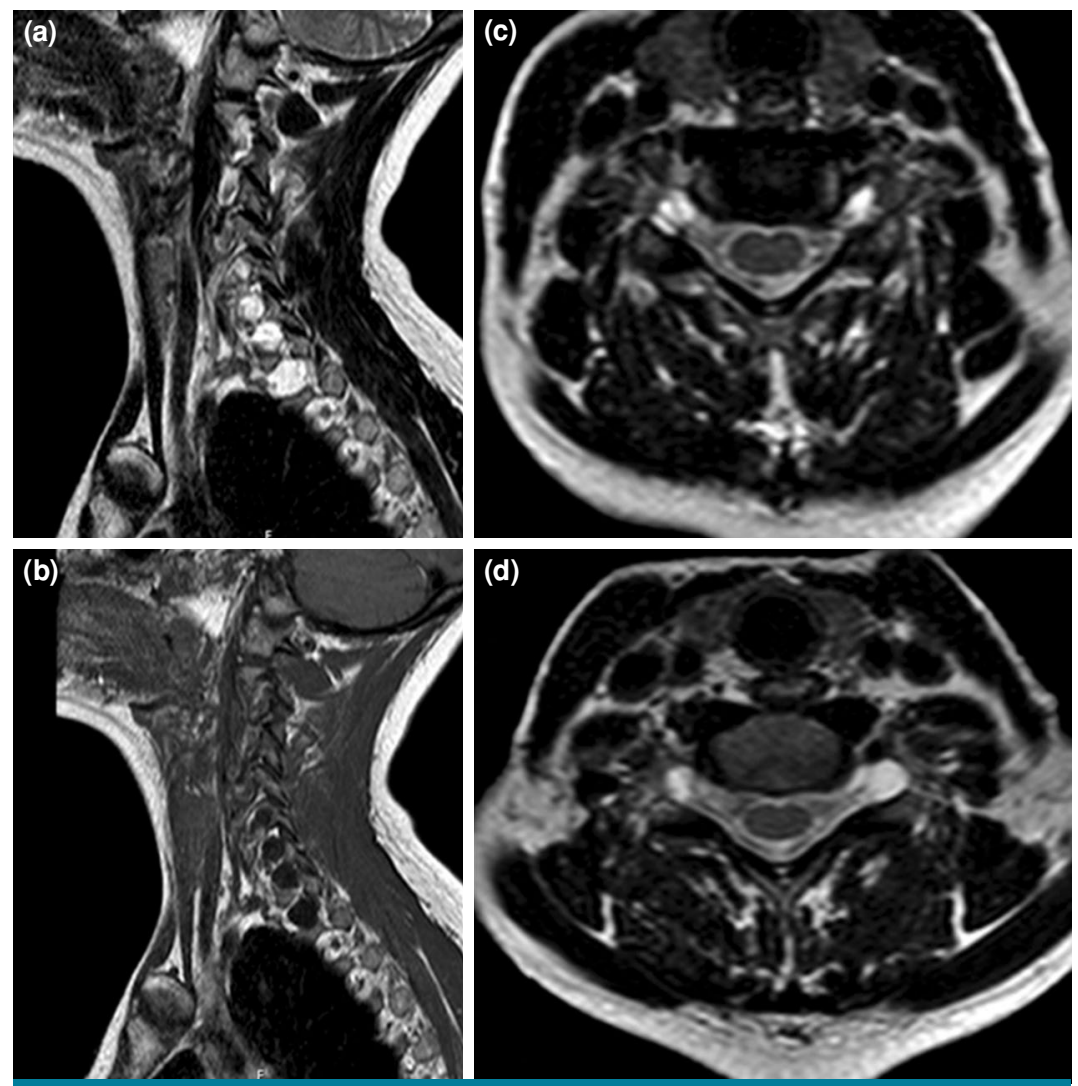

FIGURE 1. Sagittal plane of cervical spine, (a) lesions in T2 sequences and (b) in T1 sequences. Axial (C5: c, C6: d) views of perineural cysts. 
magnetic resonance imaging (MRI) for determining the reason of dorsalgia. Due to the fact that several number of perineural cysts were observed in the examination area during the procedure, the radiologic investigation was extended to cervical and sacral zones. A written informed consent was obtained from the patient.

There were 39 lesions at 17 levels in entire vertebra in MRI and more than one perineural cysts were observed adjacent to the same nerve root at several vertebrae levels. Sixteen of these lesions were in cervical, 13 were in thoracic and 10 were in lumbar spine (Table I). The cervical lesions were mean $4.11 \pm 2.56$ (range, 1.00 to 10.2$) \mathrm{mm}$, the thoracic lesions were mean $7.27 \pm 2.19$ (range, 3.30 to 12.2 ) $\mathrm{mm}$, the lumbar lesions were mean $7.12 \pm 1.92$ (range, 4.9 to 11.0 ) $\mathrm{mm}$, and no sacral lesions were seen. The mean of all lesions was $5.93 \pm 2.77$ (range, 1.00 to 12.2 ) $\mathrm{mm}$ (Figure 1).

Perineural cysts presented from the $\mathrm{C} 2$ level and the largest one at the C8 level. However, the total width of the three cysts in the C6 level was greater than C8. Also, there were perineural cysts in the thoracic spine, starting from the $\mathrm{T} 1$ level and the largest one of that also at the T1. However, the total area occupied by the cysts in the left nerve root of the T11 level with two cysts was greater than T1. In the lumbar MRI, we observed the largest perineural cysts at L2 level with $11 \mathrm{~mm}$ diameter at the left foramina (Figure 2). Perineural cysts were also investigated with MR myelography with contrast agents to evaluate the relationship between cysts and neural foramen. After the evaluation of MRI and MR myelography, no relationship was detected with neural foramen (Figure 3).

In the current patient, conservative treatment was preferred because perineural cysts were widespread throughout the spine and there was no pathological clinical finding requiring surgical treatment like neuromotor deficits. The patient was followed-up for two years and during this period, pain control was provided and functional capacity increasing exercise recommendations for muscle and posture strengthening were given. Similar complaints to first outpatient clinic visit were observed during the follow-up period, but they were not progressive.

\section{DISCUSSION}

It was reported that symptomatic perineural cysts are more common at sacral vertebrae levels. ${ }^{[8]}$ In the current case, all lesions were located over the sacral region. This may be the reason why the patient's complaints could be controlled conservatively.
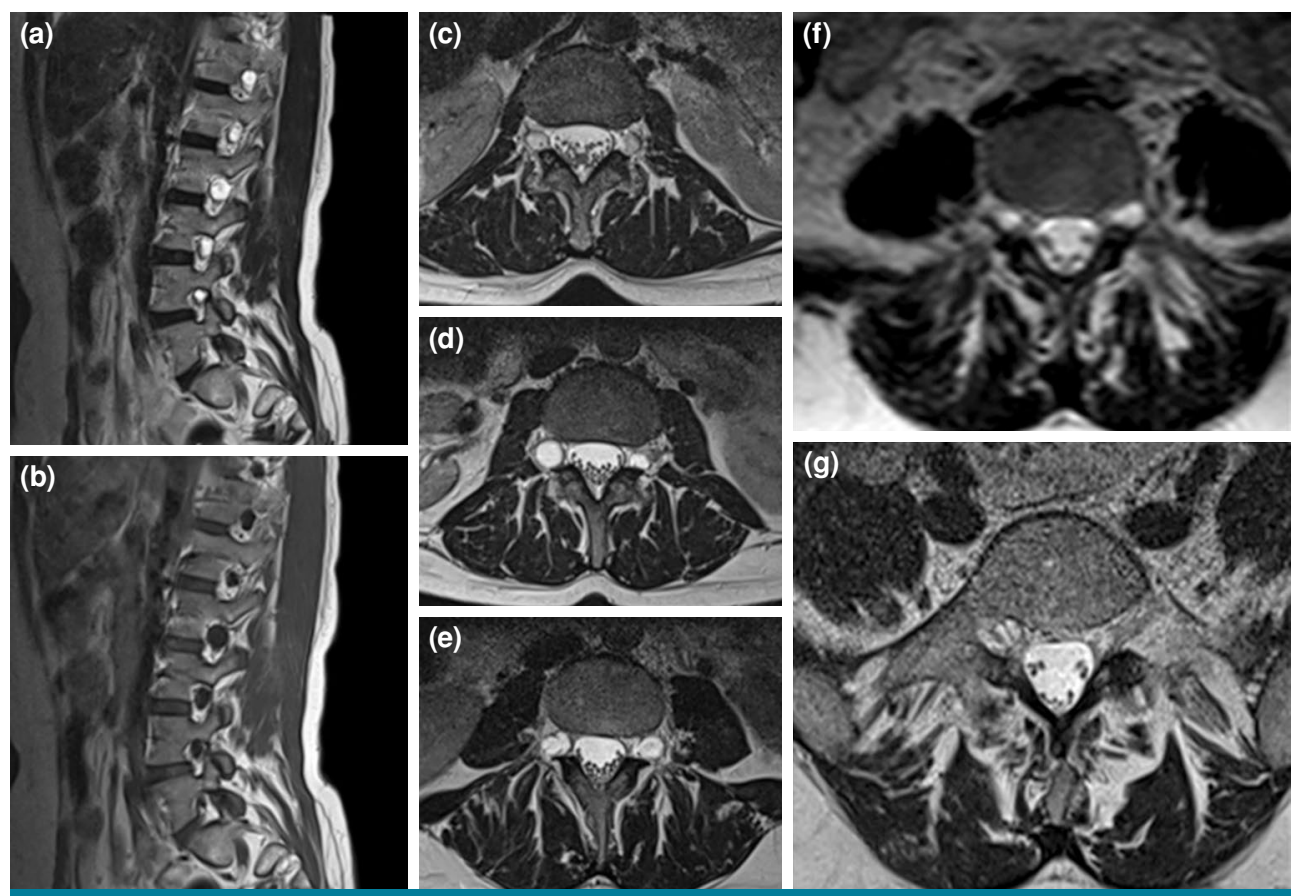

FIGURE 2. Sagittal plane of lumbar spine, (a) in T2 sequences and (b) in T1 sequences. Axial (L1: c, L2: d, L3: e, L4: f, L5: g) views of perineural cysts. 


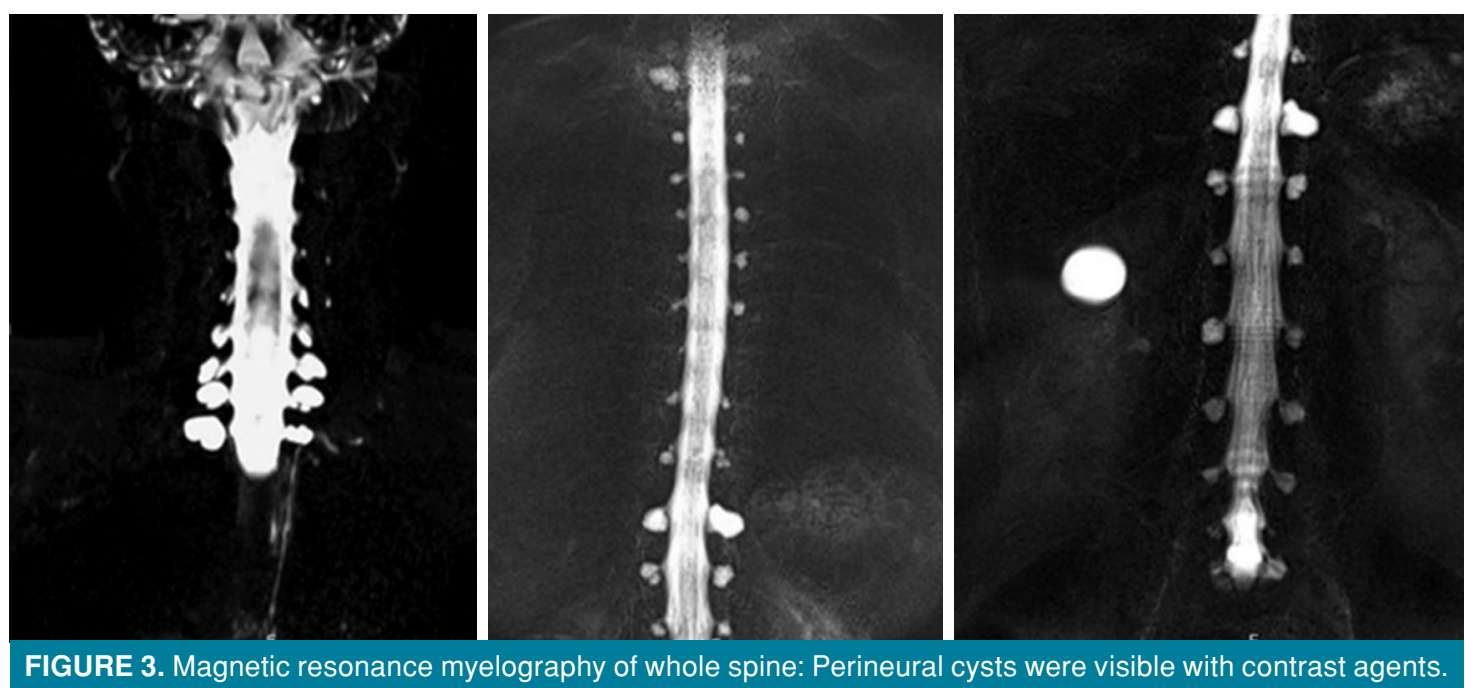

Magnetic resonance images of 842 patients were examined in terms of the presence of perineural cysts and perineural cysts were detected in $75(8.9 \%)$ patients. Twenty-two of these lesions were present as single lesion, while the maximum number of spinal levels detected in one patient was five. Only three patients had a single level of cervical lesion and 11 patients had thoracic lesion. ${ }^{[9]}$ In our case, there were 16 lesions observed in cervical region while perineural cysts in cervical region are rarely reported in the literature and most of them presented only one cyst. ${ }^{[10-12]}$

In a different study investigating perineural cysts in the sacral region, 132 patients were evaluated and it was reported that the mean number of cysts was $2.0 \pm 1.2$ (range, 1 to 6 ), and the maximum number of sacral cysts in one patient was six. In the same study, the mean diameter of the cysts was reported as $12.8 \pm 5.6$ (range, 5 to 37 ) $\mathrm{mm} \cdot{ }^{[1]}$

Perineural cysts are filled with cerebrospinal fluid and have been demonstrated by myelography studies to expand through the check-valve mechanism. Increased cerebrospinal fluid pressure leads to the expansion of perineural cysts, and the lesions become symptomatic. ${ }^{[13]}$ It was observed that in a patient with idiopathic intracranial hypertension with sacral perineural cyst, when the cerebrospinal fluid pressure returned to normal, the sacral perineural cyst shrank and symptoms improved. ${ }^{[14]}$

The reason for the smaller mean of cyst diameters in our case was thought to be due to the presence of multiple lesions and cerebrospinal fluid pressure spreading to several points at the same time, thereby allowing the lesion diameters to remain small. The presence of multiple lesions as in this case may disperse cerebrospinal fluid pressure, preventing the development of a symptomatic lesion.

In conclusion, to the best of our knowledge, this was the first case reported in the literature with multiple perineural cysts of widespread involvement of the spine. This case is a reminder that multiple perineural cysts can be a cause of dorsalgia without disc herniation or other cause of vertebral canal stenosis.

Declaration of conflicting interests

The authors declared no conflicts of interest with respect to the authorship and/or publication of this article.

\section{Funding}

The authors received no financial support for the research and/or authorship of this article.

\section{REFERENCES}

1. Kuhn FP, Hammoud S, Lefèvre-Colau MM, Poiraudeau S, Feydy A. Prevalence of simple and complex sacral perineural Tarlov cysts in a French cohort of adults and children. J Neuroradiol 2017;44:38-43.

2. Paulsen RD, Call GA, Murtagh FR. Prevalence and percutaneous drainage of cysts of the sacral nerve root sheath (Tarlov cysts). AJNR Am J Neuroradiol 1994;15:293-7.

3. Yang AI, Rinehart CD, McShane BJ, Hitti FL, Welch WC. Growth of Lumbosacral Perineural (Tarlov) Cysts: A Natural History Analysis. Neurosurgery 2020;86:88-92.

4. Tarlov IM. Spinal perineurial and meningeal cysts. J Neurol Neurosurg Psychiatry 1970;33:833-43.

5. Burke JF, Thawani JP, Berger I, Nayak NR, Stephen JH, Farkas T, et al. Microsurgical treatment of sacral perineural (Tarlov) cysts: case series and review of the literature. J Neurosurg Spine 2016;24:700-7.

6. Ju CI, Shin H, Kim SW, Kim HS. Sacral perineural cyst accompanying disc herniation. J Korean Neurosurg Soc 2009;45:185-7. 
7. Atik OŞ. What are the expectations of an editor from a scientific article? Jt Dis Relat Surg 2020;31:597-8.

8. Lucantoni C, Than KD, Wang AC, Valdivia-Valdivia JM, Maher CO, La Marca F, et al. Tarlov cysts: a controversial lesion of the sacral spine. Neurosurg Focus 2011;31:E14.

9. Burdan F, Mocarska A, Janczarek M, Klepacz R, Łosicki $M$, Patyra K, et al. Incidence of spinal perineurial (Tarlov) cysts among East-European patients. PLoS One 2013;8:e71514.

10. Kim K, Chun SW, Chung SG. A case of symptomatic cervical perineural (Tarlov) cyst: clinical manifestation and management. Skeletal Radiol 2012;41:97-101.

11. Zibis AH, Fyllos AH, Arvanitis DL. Symptomatic cervical perineural (Tarlov) cyst: a case report. Hippokratia 2015;19:76-7.

12. Lee J, Kim K, Kim S. Treatment of a symptomatic cervical perineural cyst with ultrasound-guided cervical selective nerve root block: A case report. Medicine (Baltimore) 2018;97:e12412.

13. Cantore G, Bistazzoni S, Esposito V, Tola S, Lenzi J, Passacantilli E, et al. Sacral Tarlov cyst: surgical treatment by clipping. World Neurosurg 2013;79:381-9.

14. Rodrigues TP, Rodrigues MAS, Suriano IC, Zymberg ST. Idiopathic Intracranial Hypertension Associated with Symptomatic Perineural Cysts: Presentation of 2 Cases. World Neurosurg 2018;119:17-9. 